Available online on 25.02.2021 at http://jddtonline.info
Open Access to Pharmaceutical and Medical Research
unrestricted non-commercial use(CC By-NC), provided the original work is properly cited

Open Access Full Text Article

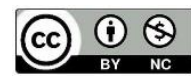

Research Article

\title{
Stability Indicating HPLC Method for the Determination of Delamanid in Pharmaceutical Dosage Form
}

\author{
Patel Advaita B. ${ }^{*}$, Patel Deepa R. ${ }^{2}$, Patel Dhaval M. ${ }^{1}$, Babaria Mansi ${ }^{3}$ \\ ${ }_{1}$ Professor, SAL Institute of Pharmacy, Ahmedabad, Gujarat, India \\ 2 Professor, Kalol Institute of Pharmacy, Gandhinagar, Gujarat, India \\ ${ }^{3}$ Student, Kalol Institute of Pharmacy, Gandhinagar, Gujarat, India
}

Article Info:

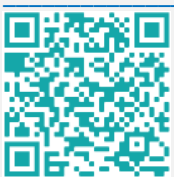

\section{Article History:}

Received 26 Dec 2020;

Review Completed 09 Feb 2021

Accepted 16 Feb 2021:

Available online 25 Feb 2021

Cite this article as:

Patel AB, Patel DR, Patel DM, Babaria M, Stability Indicating HPLC Method for the Determination of Delamanid in Pharmaceutical Dosage Form, Journal of Drug Delivery and Therapeutics. 2021; 11(1-s):108-112 DOI: http://dx.doi.org/10.22270/jddt.v11i1-s.4566

*Address for Correspondence:

Patel Advaita B., Professor, SAL Institute of Pharmacy, Ahmedabad, Gujarat, India

\section{Abstract}

Delamanid is successfully used for treatment of MDR TB. A stability indicating analytical method has been developed and validated. In this study Delamanid was degraded under different stress test conditions as per International Conference on Harmonization. The degraded samples were used to develop a stability-indicating high performance liquid chromatographic (HPLC) method for the Delamanid. The Delamanid was well separated from degradation products using a reversed-phase Hypersil BDS C18 $(250 \mathrm{~mm} \times 4.6 \mathrm{~mm}$ i.d., $5 \mu \mathrm{m}$ ) column and a mobile phase comprising of $0.01 \mathrm{M} \mathrm{pH} 2.70$ Phosphate Buffer: Acetonitrile (pH 3.50) 70:30, pH of mobile phase was adjusted with Glacial acetic acid and other HPLC parameters were flow rate $1 \mathrm{~mL} / \mathrm{min}$, detection wavelength $254 \mathrm{~nm}$ and injection volume $10 \mu \mathrm{l}$. The method was validated for linearity, precision, accuracy, ruggedness and robustness. Results obtained after validation study indicating that the proposed single method allowed analysis of Delamanid in the presence of their degradation products formed under a variety of stress conditions. The developed procedure was also applicable to the determination of stability of the Delamanid in commercial pharmaceutical dosage form.

Keywords: Delamanid, stability indicating analytical method, HPLC

\section{INTRODUCTION:}

Delamanid is effective substance used in a treatment of MDR TB. It is acknowledged by its trade name of Deltyba. ${ }^{1}$ It is the foremost in a new class of TB drugs assigned as nitroimidazoles. Chemically Delamanid is (2R)-2-Methyl-6nitro-2-[(4- $\{4-[4-$

(trifluoromethoxy)phenoxy]-1piperidinyl\} phenoxy) methyl]- 2,3-dihydroimidazo[2,1b] $[1,3]$ oxazole as shown in figure 1. Delamanid is administered to adults who are suffering with TB that is affecting the lungs, and which is multi drug resistant. It is prodrug and acts by obstruct the synthesis of mycobacterial cell wall components, methoxy mycolic acid and ketomycolic acid. ${ }^{1}$

There is no spectroscopic or chromatographic method available for its estimation. since there is need to develop the stability indicating method of the Delamanid. The aim of the present study was to develop an accurate, precise, specific, reproducible and stability indicating HPLC method for the estimation Delamanid. The Delamanid was intentionally degraded by hydrolytic, oxidative, thermal and photolytic analysis to inspect the stability and to develop stability indicating assay method. Developed method was validated as per ICH guideline by means of linearity, accuracy, precision, robustness, ruggedness, LOD, LOQ.

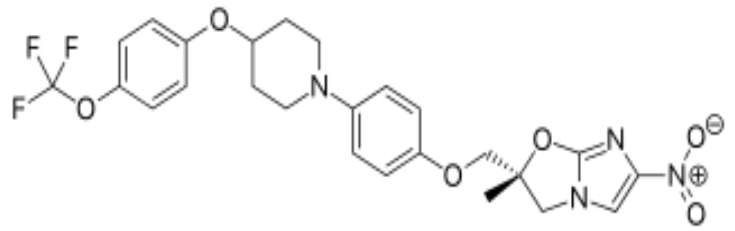

Figure 1: Structure of Delamanid

\section{MATERIALS AND METHODS:}

\section{Chemicals:}

Delamanid pure drug was procured form Green signal bio Parma private limited, Chennai, Tamilnadu. HPLC grade Acetonitrile, methanol and HPLC grade Water were purchased from Merck (India) Ltd., Mumbai, India. All other chemicals are of analytical grade from S.D. Fine Chemical Ltd., Worli, India. Tablet dosage form (Deltyba) containing 50 mg of Delamanid was procured from Indian market manufactured by Otsuka Pharmaceutical, Japan. Double distilled water and the volumetric glassware of class A grade were used all over the experimental work. Millipore membrane filters $(0.45 \mu)$ were used for filtration of mobile phase and working solution. 


\section{Instrumentation: ${ }^{2,3}$}

Analysis was performed on HPLC instrument equipped with PDA detector and Phenomenex C-18 $(250 \times 4.6 \mathrm{~mm}, 5 \mu \mathrm{m}$ particle size) column with Millennium software (Waters).Other instruments used for study were, UV visible Spectrophotometer(Analytical Technologies), Ultrasonicator (PEI), Digital Weighing balance (Shimadzu), FTIR (Analytical Technologies).

\section{Chromatographic conditions used for the method:}

Hypersil BDS C18 $(250 \mathrm{~mm} \times 4.6 \mathrm{~mm}$ i.d.,5 $5 \mathrm{~m})$ column was used for the separation with mobile phase composition $0.01 \mathrm{M} \mathrm{pH} 2.70$ Phosphate Buffer: Acetonitrile (pH 3.50) 70:30, pH of mobile phase was adjusted with Glacial acetic acid, flow rate $1 \mathrm{ml} / \mathrm{min}$, run time 20 minutes with injection volume $10.0 \mu$. Detection of drug was carried out at $254 \mathrm{~nm}$.

\section{Preparation of working standard Solution $(25 \mu \mathrm{g} / \mathrm{mL})$ :}

Accurately weighed and transferred $50.0 \mathrm{mg}$ of Delamanid in to a $100 \mathrm{ml}$ Volumetric flask, add $70 \mathrm{ml}$ diluent (Methanol) sonicate to dissolve. Make up to the volume with diluent and mixed to produce $500 \mu \mathrm{g} / \mathrm{mL}$ concentration. Dilute $5 \mathrm{ml}$ of above to $100 \mathrm{ml}$ volumetric flask. Make up to the volume with diluent and mixed to obtain $25 \mu \mathrm{g} / \mathrm{mL}$ concentration of solution.

\section{Method Validation:5,6}

\section{Linearity:}

The linearity was judged by linear regression analysis. The calibration curve was obtained with concentrations of 20$30 \mu \mathrm{g} / \mathrm{ml}$ for Delamanid as shown in figure 2 .

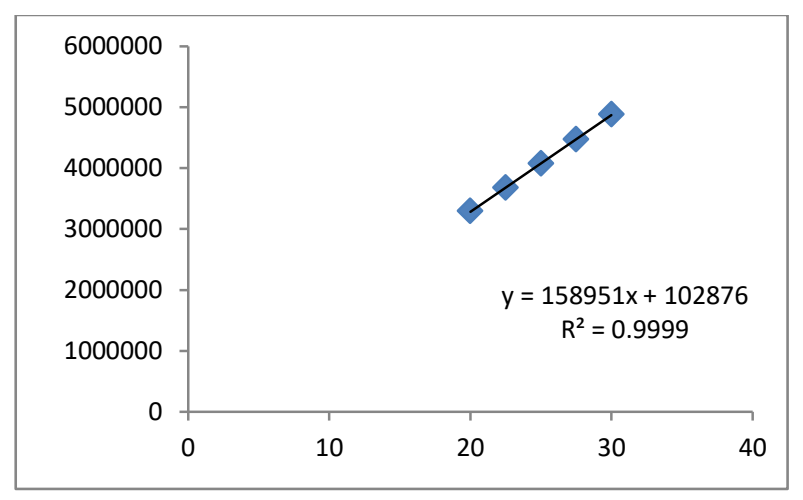

Figure 2: Calibration Curve of Delamanid

\section{Precision}

The precision of the procedure was determined by repeatability (intraday). Intraday precision was evaluated by assaying same concentration and during the same day. Repeatability of sample measurement was carried out in six different sample preparations from same homogenous blend of sample. Another replicate determination on three different days to estimate interday precision.

\section{Accuracy}

Recovery studies were performed to validate the accuracy of developed method. To a pre analysed sample solution, a definite concentration of standard drug was added and recovery was studied. A $80 \%, 100 \%$ and $120 \%$ of pure drug solutions were added to the pre analyzed samples.

\section{Analysis of Laboratory mixture}

The response of sample solution was measured at $254 \mathrm{~nm}$ using HPLC. The amounts of Delamanid were determined by regression equation.

\section{Forced Degradation of Delamanid}

\section{Acid induced degradation:}

$5 \mathrm{ml}$ of stocks solution was transferred in to $100 \mathrm{ml}$ of volumetric flask. $5 \mathrm{ml}$ of $0.1 \mathrm{~N} \mathrm{HCl}$ solutions was added and mixed well and put for $4 \mathrm{hr}$ in water bath at $40^{\circ} \mathrm{C}$.After this 5 $\mathrm{ml} 0.1 \mathrm{~N} \mathrm{NaoH}$ added to neutralize the reaction then the volume was adjusted with diluent to get $25 \mu \mathrm{g} / \mathrm{ml}$ for Delamanid.

\section{Base induced degradation:}

$5 \mathrm{ml}$ of stock solution was transferred in to $50 \mathrm{ml}$ of volumetric flask. $5 \mathrm{ml}$ of $0.1 \mathrm{~N} \mathrm{NaOH}$ solutions was added and mixed well and put for $6 \mathrm{hr}$ in water bath at $60^{\circ} \mathrm{C}$. After this 5 $\mathrm{ml} 0.1 \mathrm{~N}$ HCL added to neutralize the reaction after time period, the volume was adjusted with diluent to get $25 \mu \mathrm{g} / \mathrm{ml}$ for Delamanid.

\section{Hydrogen peroxide induced degradation:}

$5 \mathrm{ml}$ of stock solution was transferred in to $50 \mathrm{ml}$ of volumetric flask. $4 \mathrm{ml}$ of $3 \% \mathrm{H} 2 \mathrm{O} 2$ solutions was added and mixed well and put for $4 \mathrm{hr}$ at Room Temperature. After time period, the volume was adjusted with diluent to get $25 \mu \mathrm{g} / \mathrm{ml}$ for Delamanid.

\section{Thermal Degradation:}

$5 \mathrm{ml}$ of stock solution was transferred in to $100 \mathrm{ml}$ of volumetric flask. Put for $4 \mathrm{hr}$ at 105 0C Temperature in water bath. After time period the content was cooled to RT. Then the volume was adjusted with diluent to get $25 \mu \mathrm{g} / \mathrm{ml}$ for Delamanid.

\section{RESULT AND DISCUSSION:}

\section{Method Validation:}

\section{Accuracy:}

HPLC area responses for accuracy determination are illustrated in Table 1 . Good recoveries (within the range $99.51 \%-100.77 \%$ ) of the spiked drug were obtained at each added concentration; recommend that the method was accurate.

Table 1: Results of recovery study

\begin{tabular}{ccccc}
\hline Sr. No & Concentration level & Amount added & Amount recover & \%Mean recovery* \\
\hline 1 & $80 \%$ & 20 & 16 & $100.77 \%$ \\
2 & $100 \%$ & 20 & 20 & $100.46 \%$ \\
3 & $150 \%$ & 20 & 24 & $99.51 \%$ \\
\hline
\end{tabular}




\section{Precision:}

Results of intraday and interday precision study are shown in table no 2 and from results values of SD and RSD under different conditions are within the prescribed limit of $2 \%$ which indicating high precision of the method.

Table 2: Results of intraday and interday Precision

\begin{tabular}{cccccc}
\hline \multirow{2}{*}{ SR no } & Concentration $(\boldsymbol{\mu g} / \mathbf{m l})$ & \multicolumn{2}{c}{ Intraday precision } & \multicolumn{2}{c}{ Interday Precision } \\
\cline { 3 - 6 } & & Mean Area & \% RSD & Mean Area & \% RSD \\
\hline 1 & 20 & 3318926 & 0.33 & 3353993 & 0.08 \\
2 & 22.5 & 3696587 & 0.94 & 3693991 & 0.06 \\
3 & 30 & 4886813 & 0.45 & 4912877 & 0.1 \\
\hline
\end{tabular}

*Each value is mean of five observations

\section{Limit of Quantitation and Limit of detection:}

Limit of Quantitation and Limit of Detection Developed stability indicating method was able to determine limit of quantitation $0.560 \mu \mathrm{g} / \mathrm{ml}$ minimum level concentration of Delamanid with high accuracy and precision and limit of detection is $0.185 \mu \mathrm{g} / \mathrm{ml}$.

\section{Linearity and Range:}

The response for the drug was linear ( $\mathrm{r} 2=0.999)$ in the concentration range between $20-30 \mu \mathrm{g} / \mathrm{ml}$.

\section{Application of developed method on marketed formulation:}

The developed HPLC method is suitable for estimation of Delamanid as it extracts the drug from formulation and determines the percent content with good \%RSD and \% assay was found $99.47 \% \mathrm{w} / \mathrm{w}$. Chromatogram of Delamanid sample is shown in figure 3 .

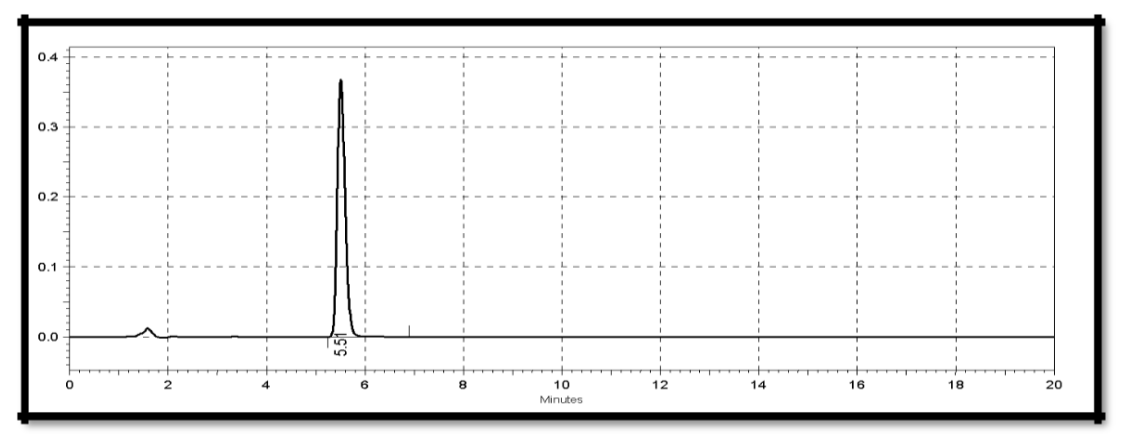

Figure 3: Chromatogram of Delamanid Sample

\section{Forced Degradation of Delamanid:}

Acid Induced Degradation Product: The chromatogram of the acid degraded sample for Delamanid showed $17.36 \%$ degradation of Delamanid as shown in figure 4.

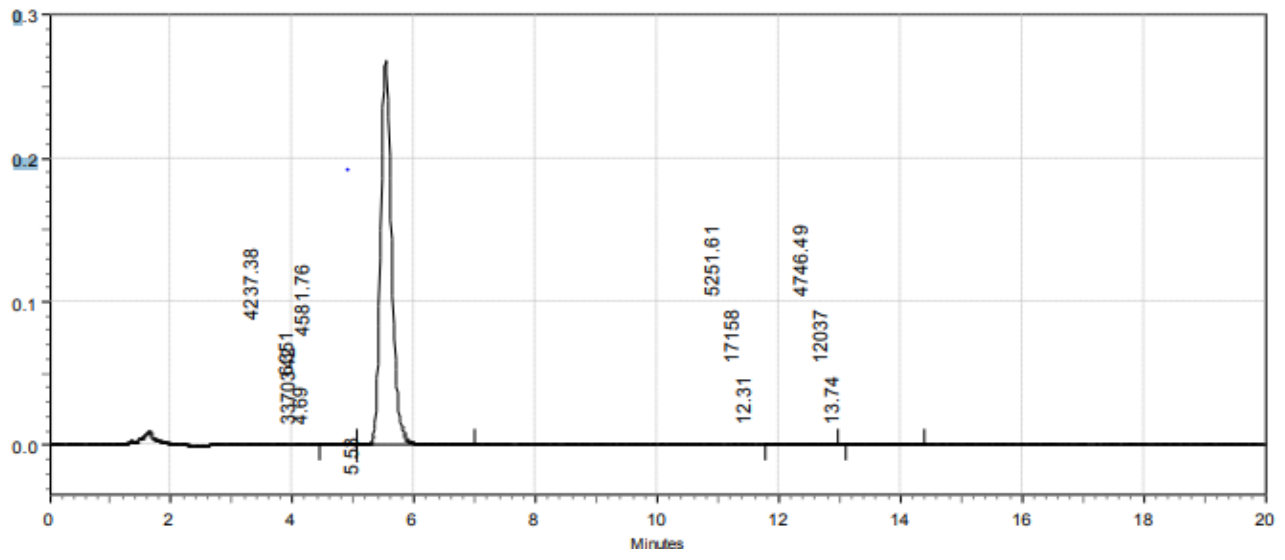

Figure 4: Chromatogram of Delamanid and its acid degradation product. 
Base Induced Degradation Product: The chromatogram of the base degraded sample for Delamanid showed additional peaks and $15 \%$ degradation of Delamanid as shown in figure 5.

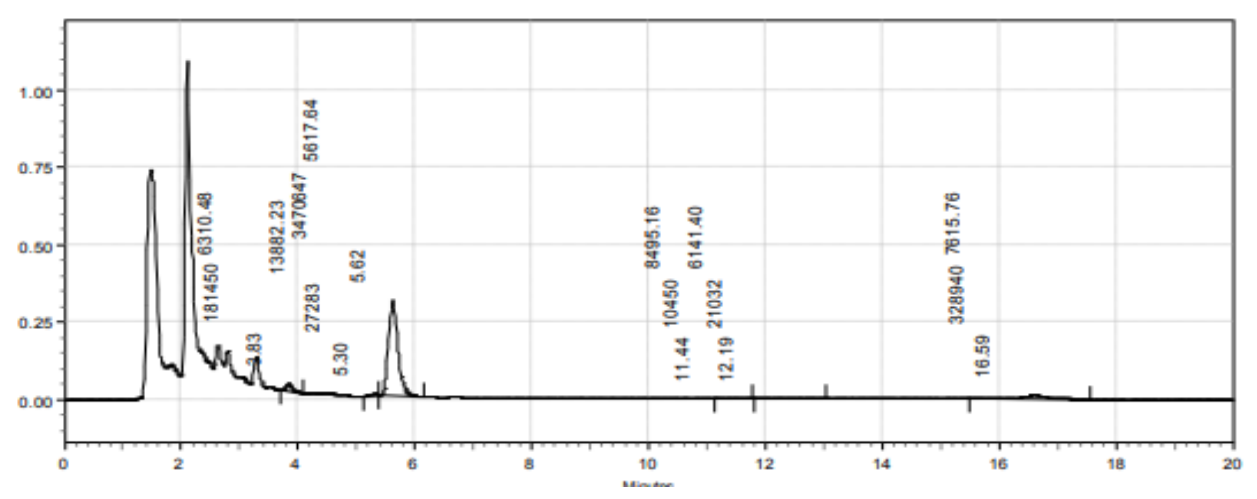

Figure 5: Chromatogram of Delamanid and its base degradation product.

Oxidation Induced Degradation Product: The

chromatogram of the oxidative degraded sample for
Delamanid showed additional peaks and $11.35 \%$ degradation of Delamanid as shown in figure 6.

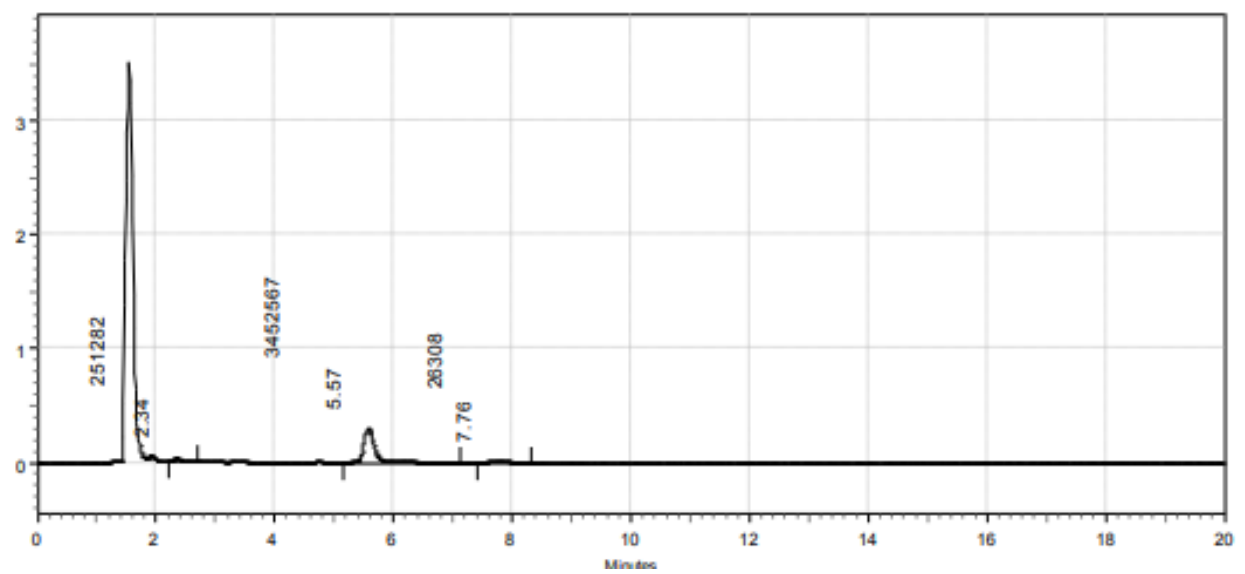

Figure 6: Chromatogram of Delamanid and its oxidadative degradation product

Thermal Degradation Product: The chromatogram of the thermally degraded sample for Delamanid showed additional peaks and $15.43 \%$ degradation of Delamanid as shown in figure 7 .

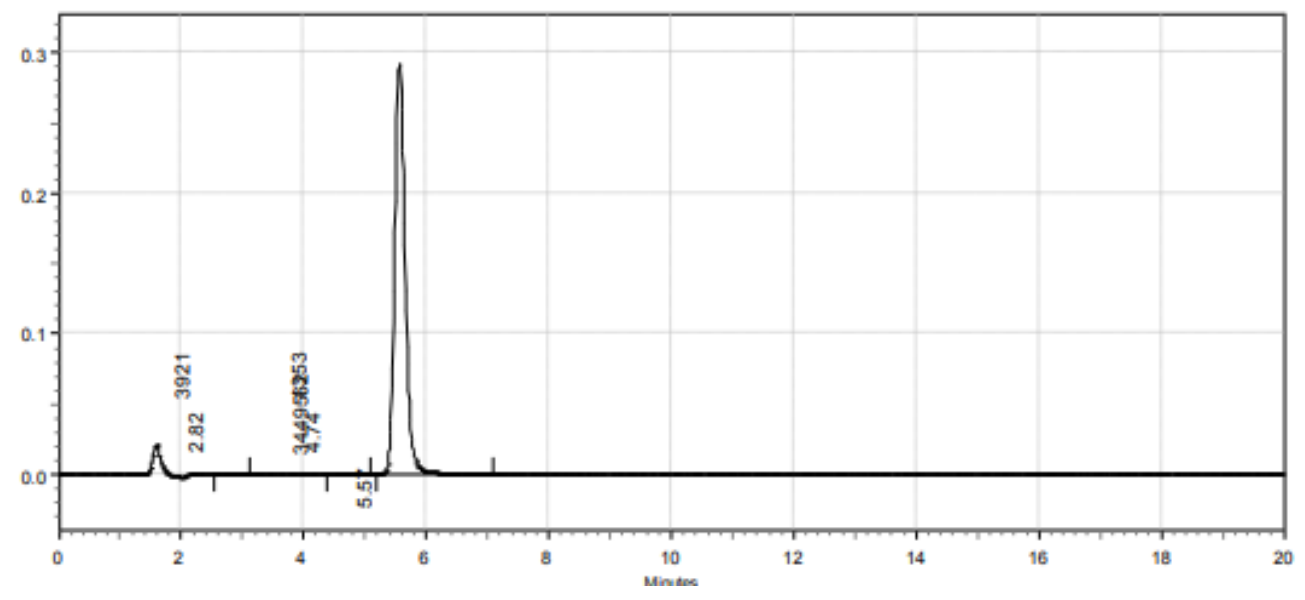

Figure 7: Chromatogram of Delamanid and its thermal degradation product 
Results of all degradation parameters are shown in table 3

Table 3: Results of Degradation study.

\begin{tabular}{lccccc}
\hline \multirow{2}{*}{ Parameter } & Time (in Hr) & \multicolumn{2}{c}{ Standard } & \multicolumn{2}{c}{ Sample } \\
\hline & & Area & \% Degradation & Area & \% Degradation \\
\hline ACID & 4 & 3370342 & 17.36 & 3325408 & 15.2 \\
BASE & 6 & 3315848 & 15 & 3470647 & 10.81 \\
Oxidation & 4 & 3630054 & 11.01 & 3452567 & 11.35 \\
Thermal & 4 & 3449562 & 15.43 & 3446424 & 12.05 \\
\hline
\end{tabular}

*Each value is mean of five observations

\section{CONCLUSION:}

The developed HPLC technique is precise, specific, accurate and stability indicating. The developed method was validated based on ICH guidelines. Statistical analysis proves that the method is repeatable and selective for the analysis of Delamanid as bulk drug and in pharmaceutical formulations.

The method can be used to determine the purity of the drug available from the various sources by detecting the related impurities. It may be extended to study the degradation kinetics of Delamanid and for estimation of pure and its metabolites in plasma and other biological fluids.

\section{REFERENCES:}

1) Stephen K. Field, Safety and Efficacy of Delamanid in the Treatment of Multidrug-Resistant Tuberculosis, Clinical medicine insight: therapeutics, 2013; 5:137-149.

2) Walker R., Cate W. Clinical Pharmacy \& Therapeutics; $4^{\text {th }}$ ed, Churchill Livingstone Elsevier, United Kingdom, 2008, p 629

3) Snyder LR., Kirkland JL., Glajch JL. Practical HPLC Method Development; $2^{\text {nd }}$ ed, Wiley Interscience, New York, 1997, p 205-227,234,266.

4) Robinson JW., Skelly EM., Frame GM. Undergraduate Instrumental Analysis; $6^{\text {th }}$ ed, Marcel Dekker, New Jersey, 2005, $\mathrm{p} 6$.

5) Patel A. B , "Analytical Method Validation: Collation between International Guidelines, Asian Journal of Research in Chemistry", 2017; 10(6):1-10.

6) ICH Harmonized Tripartite Guideline, ICH Q2 (R1); Text \& Methodology; November 2007, pp 6 